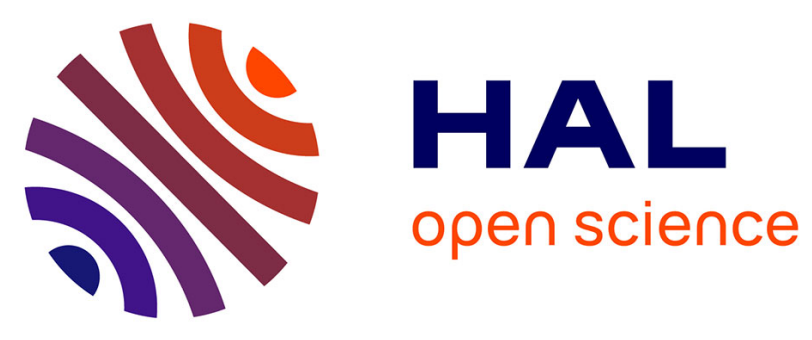

\title{
Modification of fresh state properties of Portland cement-based mortars by guar gum derivatives
}

\author{
Alexandre Govin, Marie-Claude Bartholin, Philippe Grosseau
}

\section{To cite this version:}

Alexandre Govin, Marie-Claude Bartholin, Philippe Grosseau. Modification of fresh state properties of Portland cement-based mortars by guar gum derivatives. Eleventh International Conference on Superplasticizers and Other Chemical Admixtures in Concrete, American Concrete Institute (aci); University of New Brunswick (department of civil engineering); University of Sherbrooke (department of civil engineering); University of Toronto (department of civil engineering), Jul 2015, Ottawa, Canada. pp. 315 à 332 / SP-302-24. emse-01188810

\section{HAL Id: emse-01188810 https://hal-emse.ccsd.cnrs.fr/emse-01188810}

Submitted on 31 Aug 2015

HAL is a multi-disciplinary open access archive for the deposit and dissemination of scientific research documents, whether they are published or not. The documents may come from teaching and research institutions in France or abroad, or from public or private research centers.
L'archive ouverte pluridisciplinaire HAL, est destinée au dépôt et à la diffusion de documents scientifiques de niveau recherche, publiés ou non, émanant des établissements d'enseignement et de recherche français ou étrangers, des laboratoires publics ou privés. 


\title{
Modification of fresh state properties of Portland cement-based mortars by guar gum derivatives
}

\section{By Alexandre Govin, Marie-Claude Bartholin and Philippe Grosseau}

\begin{abstract}
Synopsis: Viscosity-modifying admixtures (VMA) are often introduced in the formulation of modern factorymade mortars in order to prevent segregation and to improve the homogeneity and workability of cement-based system. Among VMAs, organic admixtures, and more especially polysaccharides such as cellulose ethers (CE), are widely used, since they improve both rheological property and water retention capacity of the mortars.
\end{abstract}

The present study examines the influence of chemical composition and structure of guar gum derivatives on water retention capacity (WR) and rheological behavior of fresh state Portland-based mortars. The investigation was also completed by adsorption isotherms. For this, original guar gum, HydroxyProplyl Guars (HPG) and hydrophobically modified HPGs were selected. The effect of the molar substitution $\left(\mathrm{MS}_{\mathrm{HP}}\right)$ and the degree of substitution $\left(\mathrm{DS}_{\mathrm{AC}}\right)$ was investigated. The results highlight that chemical composition of HPGs has a remarkable effect on fresh state properties of mortars. The original guar gum does not impact both WR and rheological behavior. Increasing $\mathrm{MS}_{\mathrm{HP}}$ leads to an improvement of the $\mathrm{WR}$ and the stability of mortars while the hydrophobic units further enhance WR and lead to a decrease in the yield stress and an increase in the resistance to the flow of admixed mortars.

Keywords: Cement; HydroxyPropyl Guar; Mortar; Rheology; Water retention. 
Alexandre Govin: Assistant Professor at the École Nationale Supérieure des Mines de Saint-Étienne, SPINEMSE, CNRS: UMR 5307, LGF, 158 Cours Fauriel, CS 62362, 42023 Saint-Étienne Cedex 2, France, E-mail: govin@emse.fr

Marie-Claude Bartholin: Laboratory technician at the École Nationale Supérieure des Mines de Saint-Étienne, SPIN-EMSE, CNRS: UMR 5307, LGF, 158 Cours Fauriel, CS 62362, 42023 Saint-Étienne Cedex 2, France, Email: bartholin@emse.fr

Philippe Grosseau: Professor at the École Nationale Supérieure des Mines de Saint-Étienne, SPIN-EMSE, CNRS: UMR 5307, LGF, 158 Cours Fauriel, CS 62362, 42023 Saint-Étienne Cedex 2, France, E-mail: grosseau@emse.fr

\section{INTRODUCTION}

Modern factory-made mortars are complex materials, in which several kinds of admixtures are added in order to obtain specific properties, from the fresh state to the hardened material. Indeed, since many years, concretes, mortars or cement grouts with high fluidity have been developed, since their use implies many economical and technical advantages. However, the use of highly flowable mixtures may lead to segregation or excessive bleeding and subsequently, durability issues. In order to overcome this problem by enhancing the sedimentation resistance while maintaining high fluidity, viscosity-enhancing admixtures (VEA) are frequently introduced within the formulation. ${ }^{1,2,3,4}$ Among these admixtures, natural polysaccharides or their derivatives (such as welan gum, starch derivatives or cellulose ethers) are the most widely used. Moreover, the incorporation of these VEAs in shotcrete or render mortar is useful to ensure sagging resistance for thick application on vertical support, and to allow sufficient fluidity for normal pumpability by supplying shear thinning rheological behavior. ${ }^{5}$ Indeed, these admixtures provide, generally, high yield stress and apparent viscosity at low shear rate but low resistance to flow at high shear rate. ${ }^{6}$ However, their mode of action is not fully understood, since results are sometimes contradictory.

Water retention (WR) is another essential property of monolayer render at fresh state. Indeed, high water retention improves the cement hydration and limits the absorption of the mixing water by a substrate and thus provides good mechanical and adhesive properties to the mortar. ${ }^{7,8}$ Among admixtures enhancing water retention capacity of the freshly-mixed mortars, cellulose ethers (CE) are the most widely used. Nevertheless, hydroxypropyl guar (HPG) are now also well-established in the construction industry as water retention agent for mortars. ${ }^{9,10,11,12}$ Moreover, HPGs are already widely used in various industrial fields, such as textile printing, hydraulic fracturing process, oil production or paper manufacturing, due to their thickening effect. ${ }^{13,14}$ Consequently, since HPGs improve the two main properties of mortar, they appear as suitable admixtures to be used in render formulation.

The aim of this study is to provide an understanding of the effect of chemical composition and structure of HPGs and its dosage on macroscopic properties of mortars. For this purpose, an original guar gum and five HPGs with specific chemical modifications, such as increase in $\mathrm{MS}_{\mathrm{HP}}$ or substitutions by hydrophobic units, were selected. The impact of admixtures on the water retention capacity and on the rheological behavior of mortars was investigated.

\section{RESEARCH SIGNIFICANCE}

Polysaccharides are commonly used in cement-based materials, but most studies focus on cellulose ethers or welan gum. Studies about hydroxypropyl guars are still scarce in the technical literature despite the fact that these molecules provide interesting properties comparable to those obtained with cellulose ethers. The aim of this study is to highlight the role of the chemical structure of hydroxypropyl guars on water retention properties and rheological properties.

\section{MATERIALS AND METHODS}

\section{Mineral products}

Mineral products used in this study consist in blend Portland cement (Holcim), lime (Holcim), calcium carbonate (Calcitec V60, Mineraria Sacilese S.p.A.) and dolomite (Bombardieri and Leidi 0.1-0.4mm). The 
mineral compositions of the commercial Portland cement, CEM II/B-LL $32.5 \mathrm{R}$ according to the European standard EN 197-1 ${ }^{15}$, used are given in Table 1.

Table 1 -Mineral composition (\%, weight) of the investigated cement determined by XRF and XRDRietveld refinement

\begin{tabular}{|c|c|c|c|c|c|c|c|}
\hline \multicolumn{4}{|c|}{ Chemical composition $(\% \mathrm{wt})$} & \multicolumn{4}{|c|}{ Phase composition (\% wt) } \\
\hline Oxides & XRF & Oxides & XRF & Phases & $\begin{array}{l}\text { XRD } \\
\text { (Rietveld) }\end{array}$ & Phases & $\begin{array}{l}\text { XRD } \\
\text { (Rietveld) }\end{array}$ \\
\hline $\mathrm{CaO}$ & 57.87 & $\mathrm{SO}_{3}$ & 3.95 & $\mathrm{C}_{3} \mathrm{~S}$ & 54.3 & Calcite & 28.9 \\
\hline $\mathrm{SiO}_{2}$ & 12.31 & $\mathrm{Na}_{2} \mathrm{O}$ & 0.99 & $\mathrm{C}_{2} \mathrm{~S}$ & 3.5 & Gypsum & 3.0 \\
\hline $\mathrm{Al}_{2} \mathrm{O}_{3}$ & 5.25 & $\mathrm{~K}_{2} \mathrm{O}$ & 1.66 & $\mathrm{C}_{3} \mathrm{~A}$ & 4.7 & Quartz & 0.9 \\
\hline $\mathrm{MgO}$ & 1.19 & $\mathrm{TiO}_{2}$ & 0.16 & $\mathrm{C}_{4} \mathrm{AF}$ & 4.6 & Free $\mathrm{CaO}$ & 0.8 \\
\hline $\mathrm{Fe}_{2} \mathrm{O}_{3}$ & 4.05 & LOI & 13.7 & & & & \\
\hline
\end{tabular}

The phase composition was determined by Rietveld refinement method (Siroquant V2.5 software) after XRD analysis (D5000, Siemens) and the oxide composition was quantified by means of X-ray fluorescence spectroscopy. The median particle diameters by volume $\left(\mathrm{d}_{50} \%\right)$, determined by means of laser diffractometry with dry powder disperser, (Mastersizer 2000 and Scirocco dispersing unit, Malvern), are $630 \mu \mathrm{m}\left(24810^{-4} \mathrm{in}\right)$, $300 \mu \mathrm{m}\left(11810^{-4} \mathrm{in}\right), 20 \mu \mathrm{m}\left(7.910^{-4} \mathrm{in}\right), 15 \mu \mathrm{m}\left(5.910^{-4} \mathrm{in}\right)$ and $5 \mu \mathrm{m}\left(1.910^{-4} \mathrm{in}\right)$ for the dolomite from Bombardieri, dolomite from Leidi, calcium carbonate, cement and lime, respectively. The particle size distribution and the specific surface area (determined by BET) are given in Fig. 1 and Table 2.

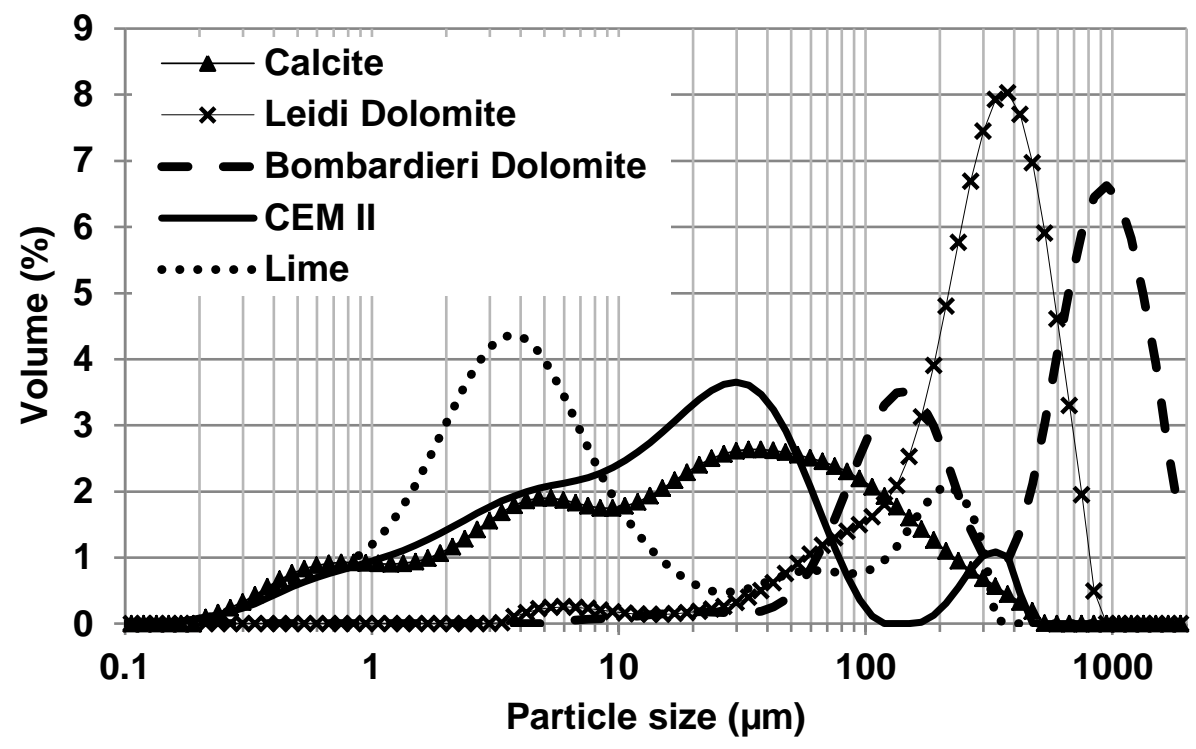

Fig. 1-Particle size distribution of raw materials constituting the mortar

Table 2 -Median particle diameters by volume $\left(d_{50}\right)$ and specific surface area of the mineral phases

\begin{tabular}{cccccc} 
& CEM II/B-LL & Lime & $\begin{array}{c}\text { Dolomite } \\
\text { Leidi }\end{array}$ & $\begin{array}{c}\text { Dolomite } \\
\text { Bombardieri }\end{array}$ & Calcite \\
\hline $\begin{array}{c}\mathrm{d}_{50}(\mu \mathrm{m}) \\
\text { BET specific }\end{array}$ & 15 & 5 & 300 & 630 & 20 \\
surface area $\left(\mathrm{m}^{2} / \mathrm{g}\right)$ & 2.40 & 5,67 & 0.43 & 0.34 & 1.44 \\
\hline
\end{tabular}

(Note: $1 \mu \mathrm{m}=0.0000394 \mathrm{in}, 1 \mathrm{~m}^{2} / \mathrm{g}=0.00488 \mathrm{ft}^{2} / \mathrm{lbm}$ )

\section{Organic admixtures}

Guar gum is a natural polysaccharide extracted from the seed endosperm of Cyamopsis tetragonolobus. This polymer consists in a $\beta(1-4)$-linked D-mannopyranose backbone with random branchpoints of galactose via an $\alpha(1-6)$ linkage (Fig.2(a)). Hydroxypropyl guars (HPGs) are obtained from the original guar gum via an irreversible nucleophilic substitution, using propylene oxide in the presence of an alkaline catalyst (Fig.2(b)). The manufacture of HPGs has the advantage of having a more reduced impact on the environment than cellulose derivatives. Indeed, guar gum is extracted by simple thermo-mechanical process, exhibits a higher chemical reactivity and is soluble in cold water thanks to its branched-chain structure with a lot of hydroxyl groups. Thus, 
the chemical modification of the original guar gum requires normal reaction conditions of temperature and pressure, does not generate large quantity of by-products, and requires minimal purification procedure. ${ }^{9}$ In this paper, five HPGs and an original guar gum provided by Lamberti S.p.A were studied. They exhibit roughly the same molecular weight, around $2.10^{6} \mathrm{~g} \cdot \mathrm{mol}^{-1}$ since they are all from the same original guar gum (noted HPG 6 in the paper). ${ }^{16}$ Table 3 provides a qualitative description of the polymers used. The qualitative substitution degrees are provided by the manufacturers. The molar substitution ratio $\left(\mathrm{MS}_{\mathrm{HP}}\right)$ represents the number of hydroxypropyl units per anhydroglucose unit and is less than 3 for the investigated HPGs. The degree of substitution (DS $\mathrm{AC}_{\mathrm{AC}}$ represents the amount of alkyl chain per anhydroglucose unit. The only difference between HPGs 1, 2 and 3 is the molar substitution ratio, which increases, while HPGs 4 and 5 exhibit an additional substitution (short alkyl chains). The $\mathrm{DS}_{\mathrm{AC}}$ of HPG 5 is higher than that of HPG 4.

Table 3 -Qualitative description of the HPG used

\begin{tabular}{cccc}
\hline & MS & DS & $\begin{array}{c}\text { Additional } \\
\text { substitution }\end{array}$ \\
\hline HPG 1 & Low & & - \\
HPG 2 & Medium & & - \\
HPG 3 & High & & - \\
HPG 4 & High & & Short alkyl chain \\
HPG 5 & High & $\begin{array}{c}\text { Higher DS } \\
\text { than HPG 4 }\end{array}$ & Short alkyl chain \\
HPG 6 & - & - & - \\
\hline
\end{tabular}

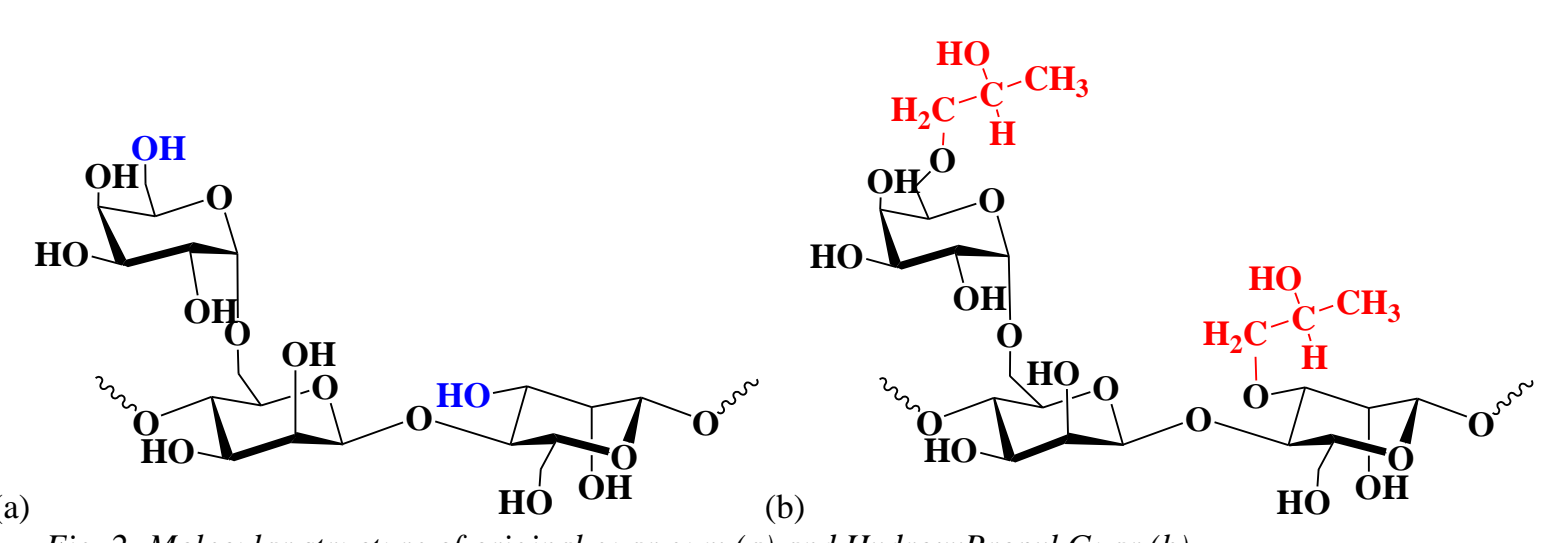

Fig. 2-Molecular structure of original guar gum (a) and HydroxyPropyl Guar (b)

\section{Methodology}

Mortars were prepared according to the following mixture proportions: $12 \%$ of cement, $3 \%$ of lime, $18 \%$ of calcium carbonate, $43 \%$ of dolomite Bombardieri and $24 \%$ of dolomite Leidi (by weight). The admixtures $(0.05$, $0.075,0.1,0.125$ and $0.15 \%$ ) were in addition to the total dry mixture (i.e. cement, lime, calcium carbonate and dolomite) and are expressed in weight percent by weight of binder (\% bwob). Dry mixture was blended in a shaker (Wab, Turbula, Germany) for $10 \mathrm{~min}$. Deionised water was added in order to obtained a liquid-to-solid ratio $\mathrm{L} / \mathrm{S}=0.22$. The mixing procedure was in accordance with EN 196-1. ${ }^{17}$ The experimental methodology consisted in dividing the freshly mixed mortar into three parts in order to characterize several properties from the same mixing. A first part was used to characterize the rheological behavior of the mortar, the water retention study was performed on the second part and the third part of the freshly mixed mortar was centrifuged in order to determine the adsorption isotherms and the polymer concentration within the pore solution following a procedure described later.

All tests were carried out, at least, in triplicate and at a controlled temperature because water retention, rheological behavior of the mortar and adsorption isotherm are temperature-dependent. A control test was also performed with a mortar without admixture.

\section{Water retention measurements}

The water retention capacity of freshly-mixed mortar can be assessed using different tests where the removed water after suction or depression is measured. ${ }^{18}$ In this study, the standard method used to estimate the water retention capacity of a mortar, was the test described in ASTM C1506-09. ${ }^{19}$ It had to be performed $15 \mathrm{~min}$ 
after mixing to measure the water loss of a mortar under depression. The standardized apparatus was submitted to a vacuum of $50 \mathrm{~mm}$ of mercury $\left(6.610^{3} \mathrm{~Pa}\right)$ for $15 \mathrm{~min}$. Then, the water retention capacity, WR, was calculated using the following equation:

$$
\mathrm{WR}(\%)=\frac{\mathrm{W}_{0}-\mathrm{W}_{1}}{\mathrm{~W}_{0}} \times 100
$$

where $\mathrm{W}_{0}$ represents the initial mass of mixing water; $\mathrm{W}_{1}$ is the loss of water mass after aspiration.

All the experiments were carried out at $23{ }^{\circ} \mathrm{C}\left(73.4{ }^{\circ} \mathrm{F}\right)$. Three classes of water retention (measured by ASTM method) of a fresh mortar can be specified according to the DTU 26.1. ${ }^{20}$ The first class (low water retention category) contains mortars that exhibit a water retention lower than $86 \%$. The second class (intermediate) corresponds to values ranging from $86 \%$ to $94 \%$. The last one (strong) is defined by water retention higher than $94 \%$, corresponding to the required values in the field of rendering application.

\section{Rheological behavior}

The rheological measurements were performed with Rheometer MCR 302 (Anton-Paar), thermostated at 20 ${ }^{\circ} \mathrm{C}\left(68{ }^{\circ} \mathrm{F}\right)$. The rheological properties of fresh mortars were investigated with vane-cylinder geometry since this system is suitable for granular pastes like mortars. ${ }^{21,22}$ The gap thickness, distance between the periphery of the vane tool and the outer cylinder, was set at $8.5 \mathrm{~mm}(0.33 \mathrm{in})$, in order to be less sensitive to the heterogeneity of the mortar. Using a Couette analogy, the shear stress and shear rate were calculated from the torque and the applied rotational velocity respectively, after calibration with glycerol. ${ }^{23}$ The mortar was introduced into the

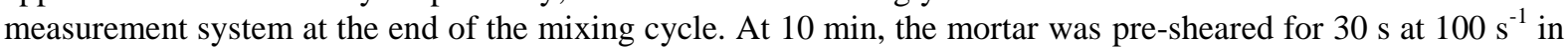
order to re-homogenize the sample and to eliminate its shear history because of thixotropic character of cementitious materials. ${ }^{24,25}$ After a period of rest of $5 \mathrm{~min}$, the rheological measurements were started (total time $=15 \mathrm{~min}$ ). At this time, the hydration rate is low enough which allows overcoming the irreversible effect of cement hydration on rheological behavior, especially at low shear rate. ${ }^{24}$ The imposed shear rate was decreased by step from 300 to $0.06 \mathrm{~s}^{-1}$ (16 steps). At each shear rate, the measuring time was adjusted in order to obtain a steady state whatever the formulation. The samples were systematically submitted to high shear rate $\left(100 \mathrm{~s}^{-1}\right)$ for $30 \mathrm{~s}$ before each imposed shear rate in order to resuspend particles of mortar within the mortar mixtures. The results were expressed as shear stress $\tau$ according to shear rate $\dot{\gamma}$ and the Herschel-Bulkley (HB) model was applied to fit the experimental data and used to describe mortars rheological behavior: ${ }^{26}$

$$
\tau=\tau_{0}+K \dot{\gamma}^{n}
$$

where $\tau_{0}$ correspond to the yield stress, $\mathrm{K}$ the consistency coefficient and $\mathrm{n}$ the fluidity index which characterizes shear-thinning behavior of mortar.

\section{Adsorption curves of HPGs on binder}

The adsorption isotherms were determined using the depletion method. The non-adsorbed polymer remaining within the pore solution was quantified by means of Total Organic Carbon (TOC) measurements. Prior to analysis, the pore solution was extracted from admixed or non-admixed mortar. The extraction was performed by means of two centrifugation steps. The first step consisted in the centrifugation of around $150 \mathrm{~g}$ $(0.30 \mathrm{lbm})$ of mortar at $5000 \mathrm{rpm}$ for $5 \mathrm{~min}$. The supernatant was, afterward, centrifuged again at $14500 \mathrm{rpm}$ for $10 \mathrm{~min}$ in order to avoid the presence of mineral particles within the solution. The supernatant was diluted with hydrochloric acid solution at $0.1 \mathrm{~mol} . \mathrm{L}^{-1}\left(0.378 \mathrm{~mol} . \mathrm{gal}^{-1}\right)$. The total organic carbon was determined by combustion at $850{ }^{\circ} \mathrm{C}\left(1562{ }^{\circ} \mathrm{F}\right)$ with a Vario-TOC Cube (Elementar). The adsorbed amount of polysaccharides was calculated from the difference of TOC content of the HPG reference solution and the TOC content of the supernatant.

\section{EXPERIMENTAL RESULTS}

\section{Impact of HPGs on the water retention property of fresh mortars}

Fig. 3 represents the evolution of the water retention capacity of fresh admixed mortars, according to the polymer dosage. The non-admixed mortar exhibits a low water retention capacity of about $72 \% \pm 0.3 \%$. Then, as expected, the water retention increases with the use of HPGs and with increasing polymer dosage, until reaching a plateau with very high WR values $(>97 \%)$. In the range of polymer dosage studied, the WR values 
reached for HPGs 2, 3, 4 and 5, are greater than 94\% and therefore belong to the strong WR class. One can also clearly notice the very limited impact of the original guar gum and, to a lesser extent, the one of HPG 1, regardless of dosage. These results suggest that the substitution of hydroxyl units from original guar gum by hydroxypropyl units increases the WR of mortars. Furthermore, the increase in the $\mathrm{MS}_{\mathrm{HP}}$ (from HPG 1 to 3 ) improves the WR capacity of mortar, since HPG 3 provides the higher WR despite lower dosage, followed by HPG 2 and then by HPG 1 .

The results highlight moreover the positive impact of additional alkyl chain on WR. Indeed, the highest WR are obtained with HPGs 4 and 5 for the lowest polymer dosages. Moreover, concerning the shape of WR curves, an abrupt change in slope can be noticed for mortars admixed with HPGs 2 to 5. This occurs for a decreasing polymer dosage from HPG 2 to HPG 3 and from HPG 3 to HPG 5.

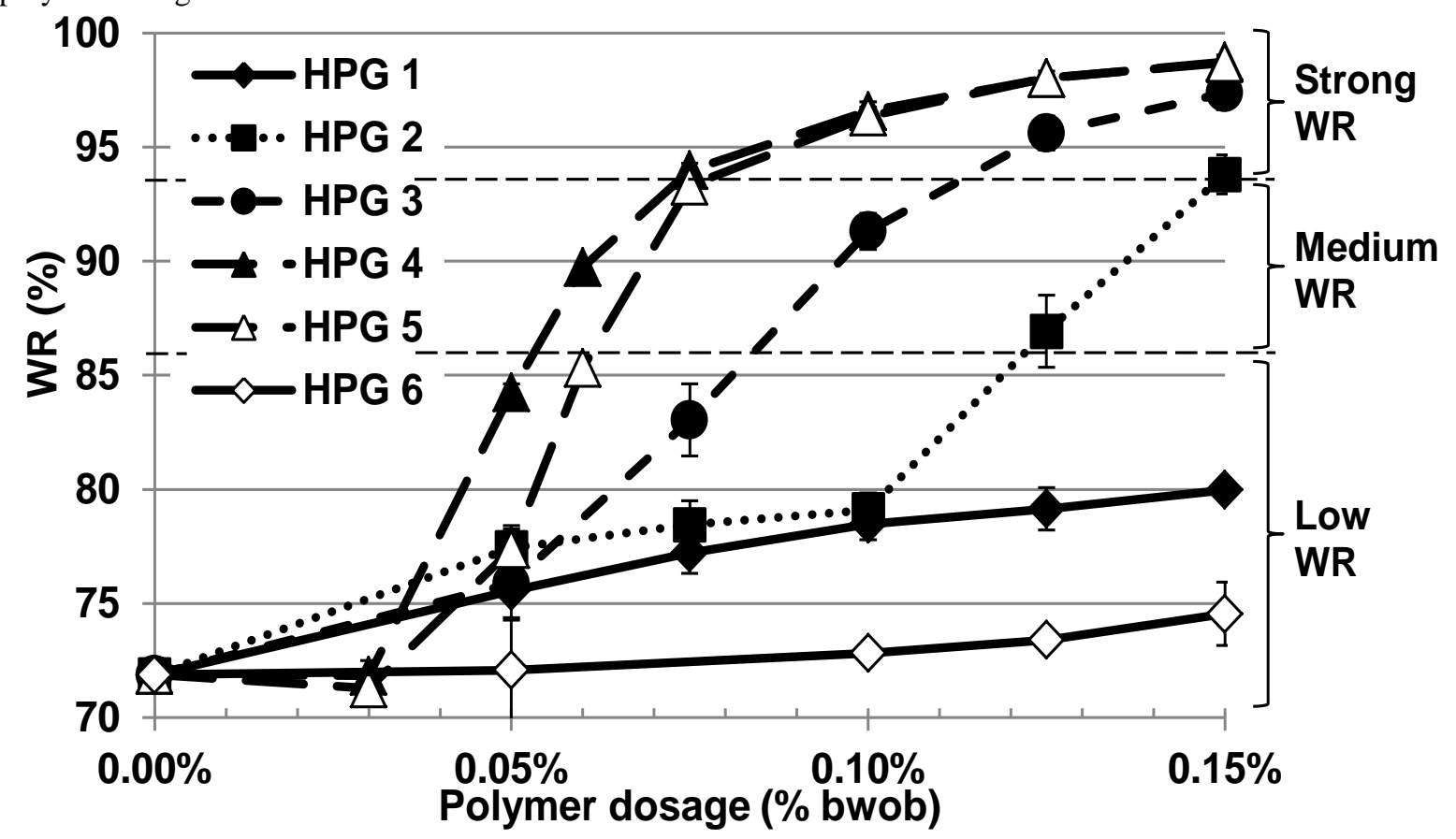

Fig. 3-Impact of polymer dosage on water retention capacity of fresh admixed mortars

\section{Adsorption curves of HPGs on binder}

Fig. 4 shows the adsorption isotherms of the hydroxypropyl guar and the original guar gum on Portland based-mortars. The results confirm the adsorption of original guar gum and HPGs on cementitious materials. It has been shown that the adsorption mechanism of galactomannose polysaccharides at solid-liquid interfaces involves strong hydrogen bonding. ${ }^{27}$ In the range of polymer dosage used in the present study, no plateau is reached, and this, whatever the admixture. For the original guar gum (HPG 6), the adsorption is totally linear (Fig. 4(a)). Moreover, its adsorption is the highest of all the tested polymers and corresponds to a total adsorption higher than $98.5 \%$ of the introduced polymer.

The presence of hydroxypropyl substitutions on the guar leads to a decrease in the affinity of the polymer with the binder since the amount of HPG 1 adsorbed is lower by 35\% than the original guar gum. Moreover, the adsorption is further reduced by the increasing values of $\mathrm{MS}_{\mathrm{HP}}$ by $46 \%$ and $64 \%$ for $\mathrm{HPG} 2$ and HPG 3, respectively, with respect to HPG 6 (Fig. 4(a)). This tendency is consistent with previous studies on HPGs and cellulose ethers $(\mathrm{CE})$. $^{10,28}$

Fig. 4(b) highlights the effect of the additional alkyl chain on the adsorption. It appears that the hydrophobic side chains slightly intensify the adsorption of the hydrophobically modified HPGs on surface of grains with respect to HPG 3. However, the adsorption of HPGs 4 and 5 is lower than that of HPG 2. For polymer dosages up to $0.1 \%$ bwob, the effect of the $\mathrm{DS}_{\mathrm{AC}}$ is negligible since the experimental data superimpose. Nevertheless, when HPG dosage is higher than $0.1 \%$ bwob, the affinity of HPG 5 with the binder becomes higher than that of HPG 4.

From the TOC measurements, the real polymer concentration within the extracted pore solution was determined. Fig. 5 shows the evolution of this concentration versus the introduced polymer dosage. Excepted HPG 6, the amount of non-adsorbed polymer increases with increasing polymer dosage. According to the HPG, the concentration rises following this order: HPG $6<\mathrm{HPG} 1<\mathrm{HPG} 2<\mathrm{HPG} 5<\mathrm{HPG} 4<\mathrm{HPG} 3$. 


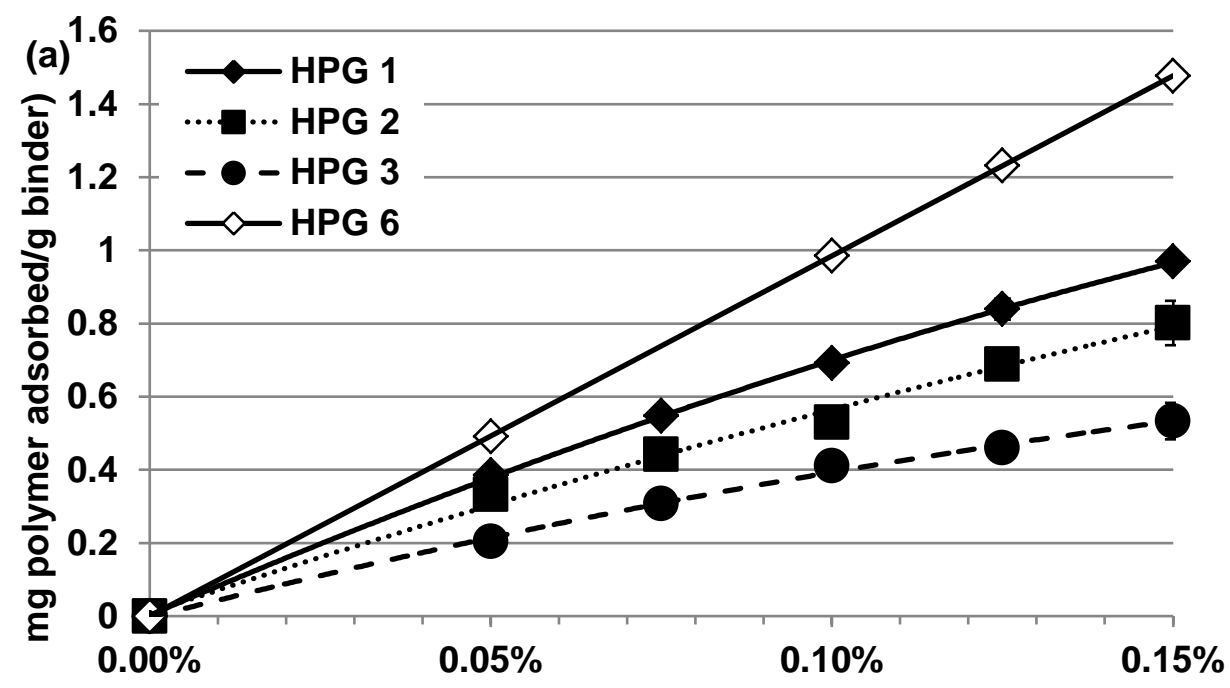

Polymer dosage (\% bwob)

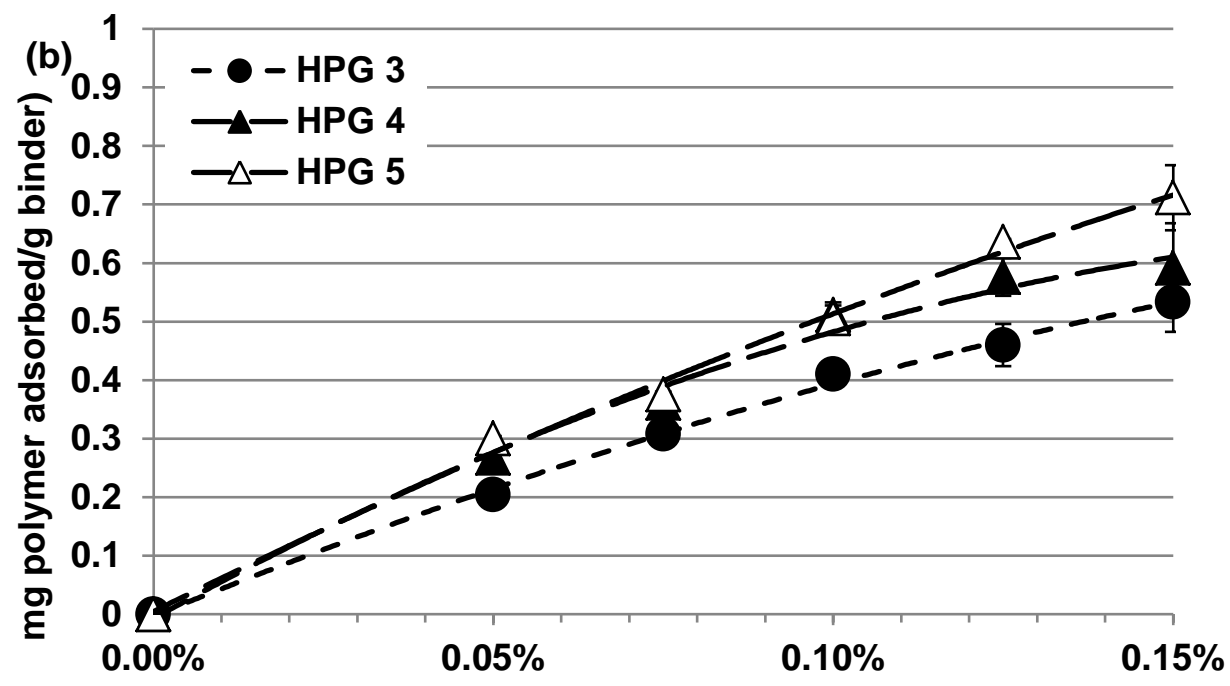

Polymer dosage (\% bwob)

Fig. 4-Adsorption isotherms of HPGs 1 to 3 and original guar gum (HPG 6) (a) and HPGs 3 to 5 (b) on binder

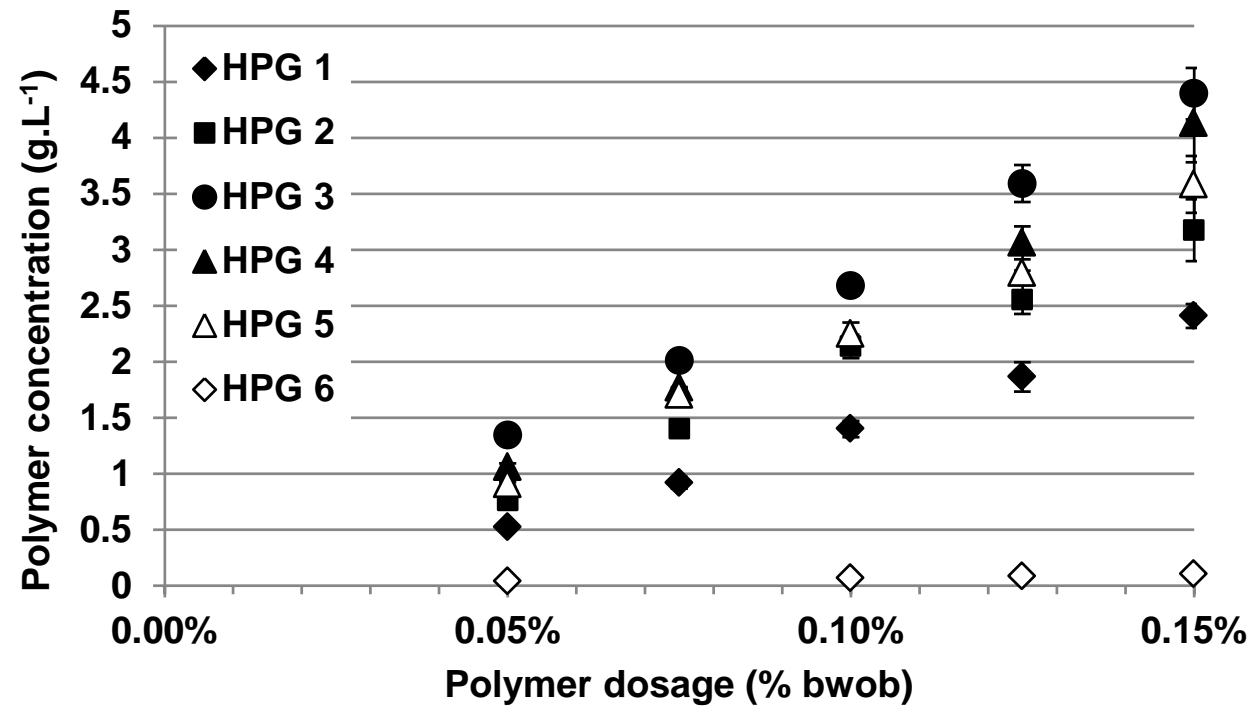

Fig. 5-Concentration of HPGs in extracted mortar pore solution 

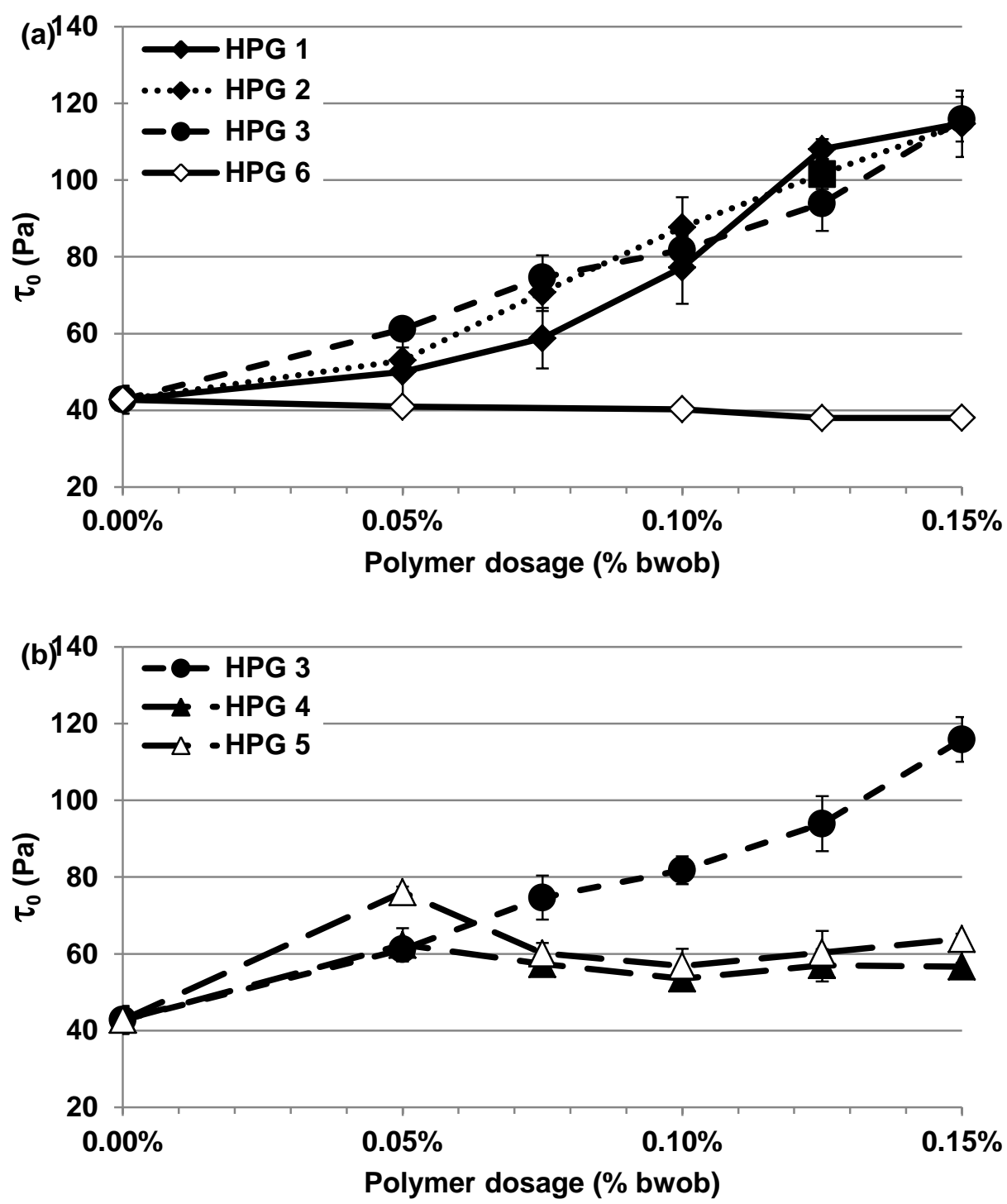

Fig. 6-Impact of polymer dosage on yield stress of fresh admixed mortars (HPGs 1 to 3 and original guar gum (HPG 6) (a) and HPGs 3 to $5(b))$

\section{Impact of HPGs on the rheological properties of fresh mortars}

The rheological results (not shown here) suggest that the thixotropy of the mortars does not affect the rheological measurements. Indeed, in the range of tested shear rates and thanks to the experimental procedure, the shear stress obtained by the increasing or decreasing shear rate ramps are superimposed which justifies the choice to consider only the decreasing ramps for all the rheological study.

Fig. 6 shows the evolution of the yield stress, extracted from Herschel-Bulkley model, for all the studied mortars with and without admixture. The mortar without admixture exhibits a yield stress value of around $45 \mathrm{~Pa}$. From the presented results, three different classes of HPG, inducing different evolution of the yield stress with the polymer dosage, can be highlighted for admixed mortars. The first category is only composed of the original guar gum (HPG 6), which induces a quasi linear decrease in the yield stress of mortar when HPG dosage increases. On the contrary, HPGs 1, 2 and 3 lead to a continuous rise of the yield stress of mortars from 50-60 $\mathrm{Pa}$ to around $120 \mathrm{~Pa}$ with the increase in the HPG dosage from $0.05 \%$ to $0.15 \%$. Finally, HPG 4 and 5 constitute the third class of admixture. The use of these admixtures leads an improvement of the yield stress compared to the non-admixed mortar, whatever the dosages tested in the study. However, the improvement is not proportional to the admixture dosage. Indeed, our first dosage ( $0.05 \%$ bwob) leads to an increase in the yield stress. Beyond this dosage, increasing the dosage provides a slow and low decrease, before reaching a plateau. The value of the yield stress reached on the plateau is still higher than that of the mortar without admixture. 

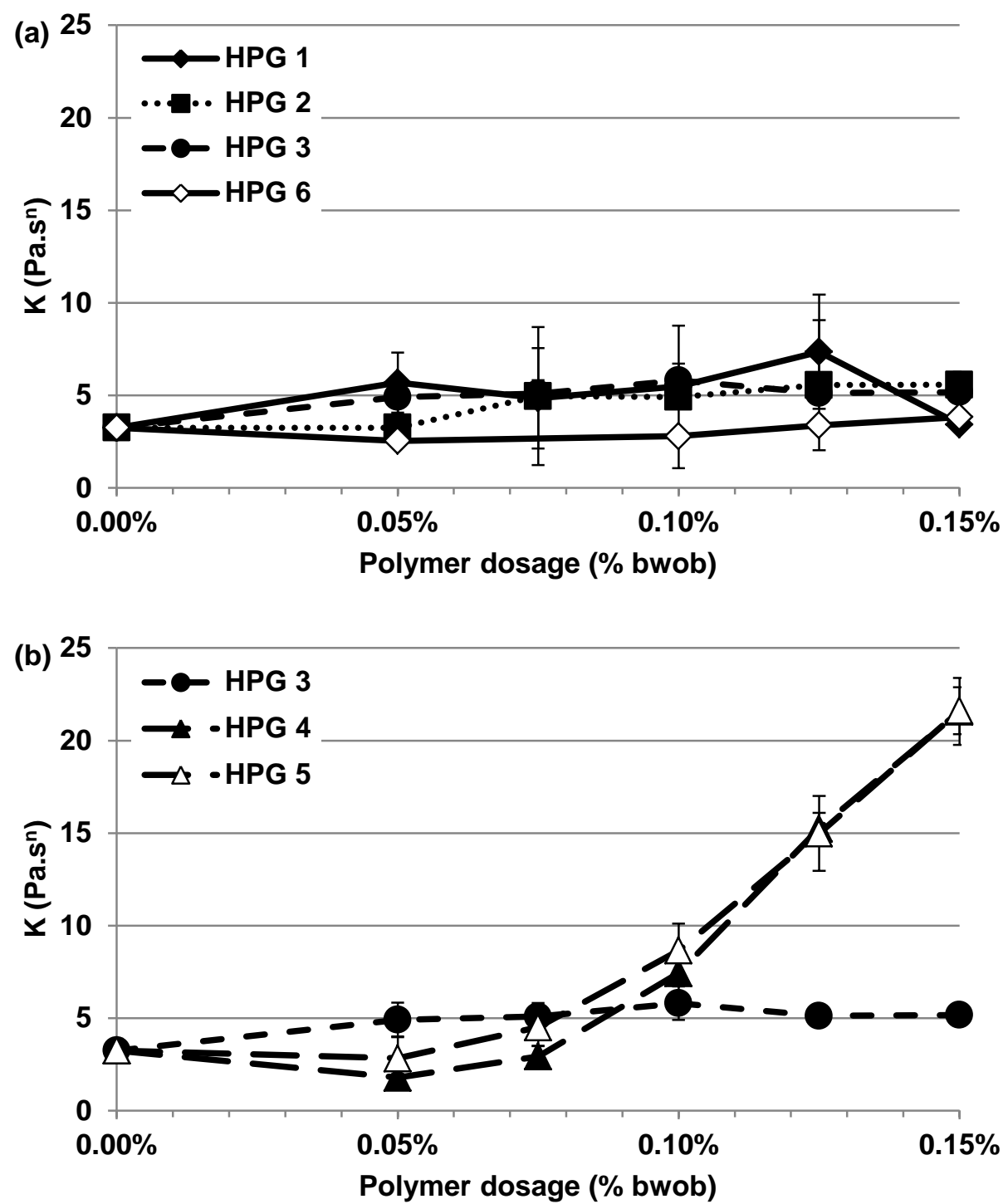

Fig. 7-Impact of polymer dosage on consistency coefficient of fresh admixed mortars (HPGs 1 to 3 and original guar gum (HPG 6) (a) and HPGs 3 to $5(b))$

The evolution of the consistency coefficient ( $\mathrm{K}$ from Herschel-Bulkley equation) during the increase of polymer dosage is presented in Fig. 7. As in the case of the yield stress, the results can be divided into three classes of polymer. The first class is only composed of the original guar gum which provides a very low or negligible modification of the consistency coefficient with increasing polymer dosage compared to non-admixed mortar. HPGs 1 to 3, constituting the second group, induce first an increase followed by a plateau in the consistency coefficient. Finally, HPGs 4 and 5 lead to a continuous increase in the consistency coefficient of admixed mortars.

Fig. 8 shows the evolution of the fluidity index (n) versus the polymer dosage for all the studied mortars. It is worth to note that whatever the mortars (non-admixed and admixed), the values of the fluidity index are lower than 1 , meaning that they are all shear thinning. Due to the high standard deviation, the value of the fluidity index of mortars admixed with HPGs 1 to 3 and HPG 6 seem to be unchanged as the dosage of HPGs increase. However, HPGs 4 and 5 leads to a low increase followed by a continuous decrease in the fluidity index until reaching values around 0.5. It means that the shear thinning behavior of mortars becomes more and more pronounced. 

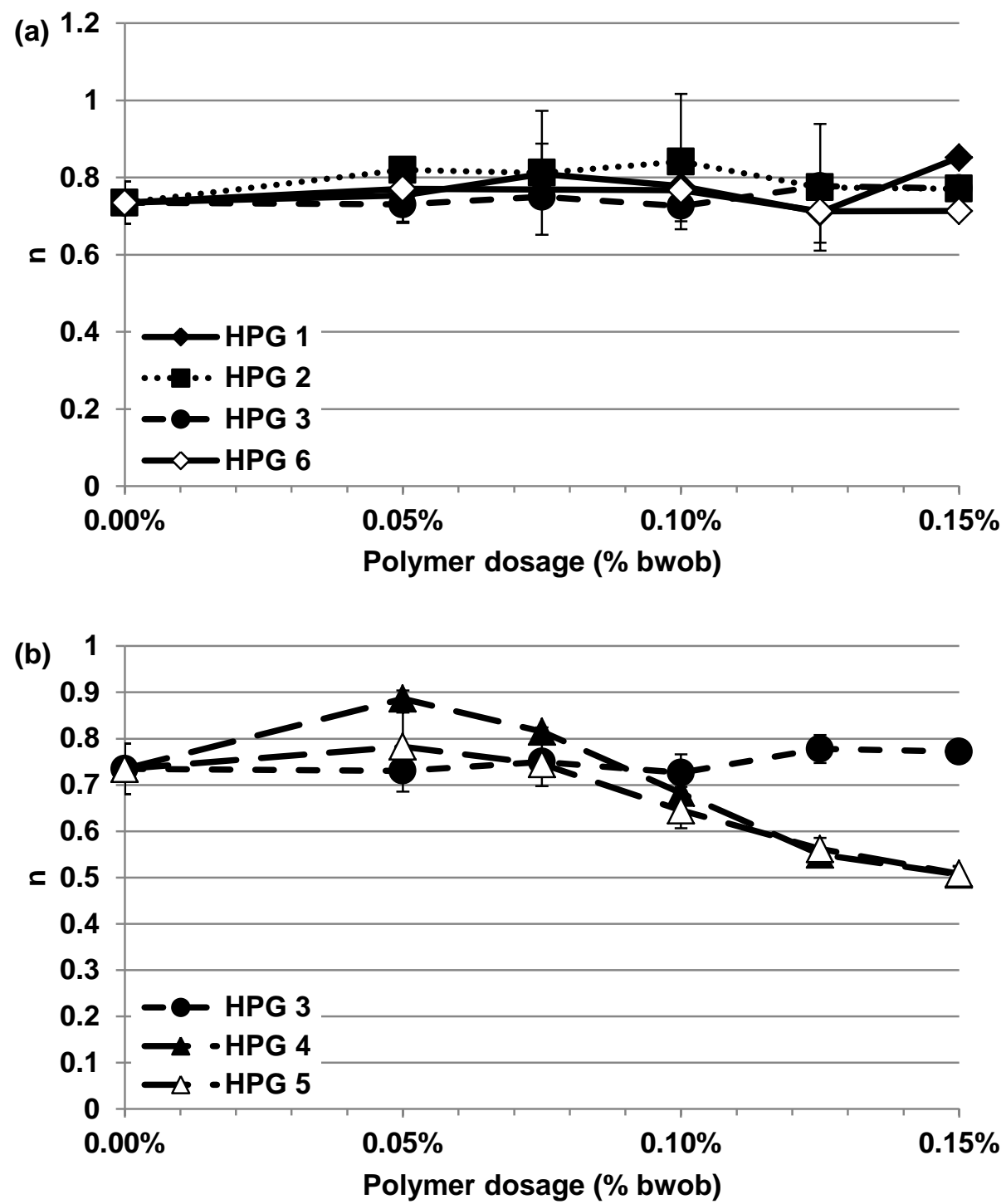

Fig. 8-Impact of polymer dosage on fluidity index of fresh admixed mortars (HPGs 1 to 3 and original guar gum (HPG 6) (a) and HPGs 3 to $5(b))$

\section{DISCUSSION}

The effect of the original guar gum (HPG 6) on the studied macroscopic properties is negligible. This result is coherent with adsorption of the polymer from the Water Retention point of view. Indeed, since the adsorption is higher than $98.5 \%$ of the initial amount of polymer, very few molecules are still in the pore solution. The composition of pore solution is thus very close to that of the non-admixed mortar, leading to similar WR.

Concerning the hydroxypropyl guar, the results from WR experiments are consistent with those of previous studies performed with HPGs or CEs and with the proposed mechanism. ${ }^{11,29,30}$ Indeed, the WR of admixed mortars is mainly governed by the ability of polysaccharidic admixtures to form a hydrocolloidal associated polymer molecules network and to induce overlapping of polymer coils within the pore solution. ${ }^{11,29,30}$ When the concentration of polymer increases in solution, the isolated polymer coils, existing at low polymer concentration, begin to come into contact with one another. This concentration is defined as the coil-overlap concentration (noted $\mathrm{C}^{*}$ ). Above this critical concentration, the polysaccharide aggregates stop the water flow by plugging the porous network of a thin polysaccharide-enriched filter cake at the interface mortar-substrate resulting in a sudden and sharp rise in WR curves. ${ }^{11}$ As previously mentioned, the abrupt change in slope is reached for a decreasing polymer dosage from HPG 1 to HPG 3. The only difference between these HPGs is the increasing substitution degree. According to literature, the increase in $\mathrm{MS}_{\mathrm{HP}}$ does not lead to a change in the $\mathrm{C}^{*}{ }^{31}$ However, the increasing substitution degree leads to a decrease in polymer adsorption on mortar 
components (Fig. 4) and hence an increase in polymer amount in pore solution (Fig. 5). Consequently, the coil overlapping occurs at lower dosage. The results highlight furthermore the positive impact of additional alkyl chain on WR. The presence of additional alkyl chains (HPG 4 and 5), despite slightly higher adsorption than HPG 3, leads to the formation of polymer associates at lower polymer dosage. Indeed, the interconnection between alkyl chains creates intramolecular and intermolecular interactions through specific hydrophobic interactions which cause a decrease in the coil-overlapping concentration. ${ }^{32,33,34}$ Consequently, the abrupt change in slope is reached for a lower polymer dosage of HPG 4 and 5 than HPG 3. However, an increase in the $\mathrm{DS}_{\mathrm{AC}}$ (from HPG 4 to 5) can lead to a conversion of some intermolecular associations to intramolecular associations and hence an increase in the polymer dosage necessary to reach coil overlap. ${ }^{31}$

The rheological results (Fig. 6, Fig. 7 and Fig. 8) highlight that HPGs 1 to 3, HPGs 4 to 5 and HPG 6 behave quite differently. Indeed, HPGs 1-2-3 lead to a continuous increase in the yield stress, while HPGs 4-5 modify mainly the consistency coefficient and the fluidity index. This means that HPGs 1-3 increase the stability of mortars while HPGs 4-5 increase the resistance to the flow of admixed mortars. HPGs 1 to 3 affect the rheological behavior of the admixed mortars in the same way, i.e. an increase in the yield stress, a low increase followed by a plateau in the consistency coefficient and a negligible modification of the fluidity index when the polymer dosage rises. Fig 4 shows that HPGs adsorb onto particles constituting the mortar. Prima facie, this adsorption could be responsible for the increase in the yield stress because of bridging flocculation. ${ }^{28}$ However, despite a strong drop of the adsorption (50\%) with the increase in the $\mathrm{MS}_{\mathrm{HP}}$ (from HPG 1 to 3) the yield stress also increases. This suggests that the non-adsorbed polymer may be responsible for the yield stress increase. The potential loss of bridging can be compensated by an increase in the pore solution viscosity induced by the rise in the polymer concentration and/or by the depletion flocculation induced by the non-adsorbed coils (Fig. 5). ${ }^{35}$

Moreover, the presence of HPG coils within the pore solution leads to an increase in the consistency coefficient $(\mathrm{K})$ compared to non-admixed mortars. However, the expected increase in $\mathrm{K}$ due to the rise of pore solution viscosity with the polymer dosage can be compensated by steric hindrance, leading to a plateau for K.

Since the adsorption of HPG 6 onto the surface of the binder is higher than $98.5 \%$, one expects to detect a very strong increase in the yield stress compared to non-admixed mortar. However, the rheological behavior of the admixed mortar with the original guar gum is very close to that of the non-admixed mortar. This result suggests that the entire molecule of the original guar gum could be mainly adsorbed onto the surface of only one particle, limiting therefore the bridging flocculation. The very high concentration of free hydroxide groups on the backbone of the guar could be responsible of this mechanism. Moreover, the adsorption of the guar molecule onto a single particle leads to an increase in the steric hindrance and in the dispersion and lubrication effects, leading to a low but continuous decrease in the yield stress. For dosages higher than $0.1 \%$ bwob, the concentration in polymer coils (HPG 6) into the pore solution begins to increase slightly (Fig. 5), leading to the beginning of the increase in the consistency coefficient and of the decrease in the fluidity index.

The additional alkyl chain also modifies the rheological properties of mortars. Contrary to HPG 3, HPGs 4 and 5 lead to a strong and continuous increase in the consistency coefficient and a decrease in the fluidity index. These results highlight that mortars become more and more shear-thinning since the fluidity index decreases from 0.8 to 0.5 . This rheological behavior gets more pronounced as the HPG dosage increases. These results are consistent with the fact that the hydrophobically modified HPGs leads to the formation of coil overlapping at lower HPG dosage $(0.05 \%$ in this study) since the presence of additional alkyl chains enhances the entanglement. Above this dosage, entanglement occurs between polymer coils, inducing a shear thinning behavior to the solution. At low shear rate, the entanglement of polymer coils leads to a higher pore solution viscosity and thus higher mortar viscosity. When the shear rate increases, the polysaccharide chains align in the direction of the flow resulting in less and less effect on mortar fluidity. The shear thinning behavior of the solution, and thus of the mortars, amplify with the increasing polymer dosage. The yield stress is also impacted by the additional alkyl chain. Indeed, $\tau_{0}$, of mortar admixed with HPGs 4 and 5 , increases for a dosage equal to $0.05 \%$ bwob then slowly decreases for dosages ranging from $0.05 \%$ to $0.075 \%$ bwob, before reaching a plateau for higher dosages $\left(\tau_{0}\right.$ reached is still higher than that of the non-admixed mortar). This result could be explained by a change in the HPG conformation due to the presence of additional alkyl chains. Indeed, as previously mentioned, alkyl chain creates intramolecular and intermolecular interactions through specific hydrophobic interactions. Intramolecular association of hydrophobic units tends to force the polymer chain into a more compact conformation. ${ }^{34,36}$ Moreover, the conformation of hydrophobically modified polymers in aqueous solution involves the presence of alkyl chains mainly inside the coils in order to limit contacts between hydrophobic chains and water. ${ }^{34}$ Consequently, the hydrophilic groups, such as hydroxyl and hydroxypropyl, are preferentially on the outskirts of the coils, promoting the adsorption onto the surface of particles (Fig. 4 (b)) and therefore steric hindrance which implies a prevention of direct contacts between particles. Moreover, due to a 
more compact conformation and avoidance between water and hydrophobic units, the bridging ability of hydrophobically modified HPGs should decrease. All these points should lead to a decrease in the yield stress.

\section{CONCLUSIONS}

In this paper, we studied the effect of several guar gum derivatives on water retention property and rheological behavior of mortars. Based upon the results, it was found that the original guar gum was totally adsorbed onto particle surface, leading to a negligible modification of WR and rheological behavior with respect to the non-admixed mortar. Depending of the chemical structure of HPGs, it is possible to promote the water retention according to two different ways. First, by increasing the $\mathrm{MS}_{\mathrm{HP}}$ of HPGs, the amount of adsorbed polymer drops, which leads to an increase in the HPG concentration within the pore solution and therefore to lower HPG dosage necessary to reach coil overlapping. Second, by enhancing overlapping, the hydrophobically modified HPGs improve the effectiveness of WR agent at low dosage. HPGs also modify the rheological behavior of the mortars. As in the case of WR, the hydrophobic characteristic of HPGs is the preponderant parameter. Indeed, it was shown that additional alkyl chain mainly leads to a more shear thinning behavior of the mortar and to a rise in the consistency coefficient, while classical HPGs strongly increases the yield stress.

\section{ACKNOWLEDGEMENTS}

The authors would like to acknowledge Lamberti S.p.A. for the provided products and for their technical and financial support.

\section{REFERENCES}

1. Rols, S.; Ambroise, J.; and Péra, J.; "Effects of different viscosity agents on the properties of self-leveling concrete", Cement and Concrete Research, V. 29, No. 2, 1999, pp. 261-266.

2. Khayat, K.H.; and Yahia, A.; "Effect of welan gum-high-range water reducer combinations on rheology of cement grout", ACI Materials Journal, V. 94, No. 5, 1997, pp. 365-372.

3. Lachemi, M.; Hossain, K.M.A.; Lambros, V.; Nkinamubanzi, P.-C.; and Bouzoubaâ, N.; "Self-consolidating concrete incorporating new viscosity modifying admixtures", Cement and Concrete Research, V. 34, No. 6, 2004, pp. 917-926.

4. Sonebi, M.; "Rheological properties of grouts with viscosity modifying agents as diutan gum and welan gum incorporating pulverised fly ash", Cement and Concrete Research, V. 36, No. 9, 2006, pp. 1609-1618.

5. Paiva, H.; Silva, L.M.; Labrincha, J.A.; and Ferreira, V.M.; "Effects of a water-retaining agent on the rheological behaviour of a single-coat render mortar", Cement and Concrete Research, V. 36, No. 7, 2006, pp. $1257-1262$.

6. Khayat, K.H.; "Viscosity-enhancing admixtures for cement-based materials - an overview", Cement and Concrete Composites, V. 20, No. 2-3, 1998, pp. 171-188.

7. Bertrand, L.; Maximilien, S.; and Guyonnet, R.; "Wedge Splitting Test: a test to measure the polysaccharide influence on adhesion of mortar on its substrate", International Congress on Polymers in Concrete, Berlin, 2004.

8. Jenni, A.; Holzer, L.; Zurbriggen, R.; and Herwegh, M.; "Influence of polymers on microstructure and adhesive strength of cementitious tile adhesive mortars". Cement and Concrete Research. V. 35, No. 1, 2005, pp. 35-50.

9. Biasotti, B.; Giudici, M.; Langella, V.; and Pfeiffer, U.; "Highly substituted hydroxypropylguar: a strong contribution to construction chemistry", International Dry mix Mortar Conference, Nürnberg, 2011.

10. Poinot, T.; Govin, A.; and Grosseau, P.; "Impact of hydroxypropylguars on the early age hydration of Portland cement", Cement and Concrete Research, V.44, 2013, pp. 69-76.

11. Poinot, T.; Govin, A.; and Grosseau, P.; "Importance of coil-overlapping for the effectiveness of hydroxypropylguars as water retention agent in cement-based mortars", Cement and Concrete Research, V.56, 2014, pp. 61-68.

12. Cappellari, M.; Daubresse, A.; and Chaouche, M.; "Influence of organic thickening admixtures on the rheological properties of mortars: Relationship with water-retention", Construction and Building Materials, V. 38, 2013, pp. 950-961.

13. Risica, D.; Barbetta, A.; Vischetti, L.; Cametti, C.; and Dentini, M.; "Rheological properties of guar and its methyl, hydroxypropyl and hydroxypropyl-methyl derivatives in semidilute and concentrated aqueous solutions", Polymer, V. 51, No. 9, 2010, pp. 1972-1982.

14. Lapasin, R.; De Lorenzi, L.; Pricl, S.; and Torriano, G.; "Flow properties of hydroxypropyl guar gum and its long-chain hydrophobic derivatives", Carbohydrate Polymer, V. 28, No. 3, 1995, pp. 195-202.

15. Standard EN 197-1, "Cement - Part 1: Composition, specifications and conformity criteria for common cements", 2012. 
16. Poinot, T.; Benyahia, K.; Govin, A.; Jeanmaire, T.; and Grosseau, P.; "Use of ultrasonic degradation to study the molecular weight influence of polymeric admixtures for mortars", Construction and Building Materials, V. 47, 2013, pp. 1046-1052.

17. Standard EN 196-1, "Methods of testing cement - Part 1: Determination of strength", 2006.

18. Patural, L.; Marchal, P.; Govin, A.; Grosseau, P.; Ruot, B.; and Devès, O.; "Cellulose ethers influence on water retention and consistency in cement-based mortars", Cement and Concrete Research, V. 41, No. 1, 2011, pp. 46-55.

19. Standard C1506-09, "Standard test Method for Water Retention of Hydraulic Cement-Based Mortars and Plasters". American Society for Testing and Material, 2009.

20. NF DTU 26.1, “Travaux d'enduits de mortiers “, 2008.

21. Bouras, R.; Kaci, A.; and Chaouche, M.; "Influence of viscosity modifying admixtures on the rheological behavior of cement and mortar pastes", Korea-Australia Rheology Journal, V. 24, No. 1, 2012, pp. 35-44.

22. Barnes, H.A.; and Nguyen, Q.D.; "Rotating vane rheometry - a review", Journal of Non-Newtonian Fluid Mechanics, V. 98, No. 1, 2001, pp. 1-14.

23. Ait-Kadi, A.; Marchal, P.; Choplin, L.; Chrissemant, A.S.; and Bousmina, M.; "Quantitative analysis of mixer-type rheometers using the Couette analogy”, The Canadian Journal of Chemical Engineering, V. 80, No. 6, 2002, pp. 1166-1174.

24. Phan, T.H.; Chaouche, M.; and Moranville, M.; "Influence of organic admixtures on the rheological behaviour of cement pastes", Cement and Concrete Research, V. 36, No. 10, 2006, pp. 1807-1813.

${ }^{25}$. Roussel, N.; Ovarlez, G.; Garrault, S.; and Brumaud, C.; "The origins of thixotropy of fresh cement pastes", Cement and Concrete Research, V. 42, No. 1, 2012, pp. 148-157.

26. Herschel, W.M.; and Bulkley, R.; "Measurements of consistency as applied to rubber-benzene solutions", Proceedings of the American Society for the Testing of Materials, Vol. 26, 1926, pp. 621-633.

27. Wang, J.; Somasundaran, P.; and Nagaraj, D.R.; “Adsorption mechanism of guar gum at solid-liquid interfaces", Minerals Engineering, V. 18, No. 1, 2005, pp. 77-81.

28. Brumaud, C.; Baumann, R.; Schmitz, M.; Radler, M.; and Roussel, N.; "Cellulose ethers and yield stress of cement pastes", Cement and Concrete Research, V. 55, 2014, pp. 14-21.

29. Bülichen, D.; Kainz, J.; and Plank, J.; "Working mechanism of methyl hydroxyethyl cellulose (MHEC) as water retention agent", Cement and Concrete Research, V. 42, No. 7, 2012, pp. 953-959.

30. Marliere, C.; Mabrouk, E.; Lamblet, M.; and Coussot, P.; "How water retention in porous media with cellulose ethers works", Cement and Concrete Research, V. 42, No. 11, 2012, pp. 1501-1512.

31. Volpert, E.; Selb, J.; and Candau, F.; "Influence of the Hydrophobe Structure on Composition, Microstructure, and Rheology in Associating Polyacrylamides Prepared by Micellar Copolymerization", Macromolecules, V. 29, 1996, pp. 1452-1463

32. Cheng, Y.; Brown, K.M.; and Prud'homme, R.K.; "Characterization and Intermolecular Interactions of Hydroxypropyl Guar Solutions", Biomacromolecules, V. 3, No. 3, 2002, pp. 456-461.

33. Semenov, A.N.; Joanny, J.-F.; and Khokhlov, A.R.; "Associating polymers: equilibrium and linear viscoelasticity", Macromolecules, V. 28, 1995, pp. 1066-1075.

34. Simon, S.; Dugast, J.; Le Cerf, D.; Picton, L.; and Muller, G.; “Amphiphilic polysaccharides. "Evidence for a competition between intra and intermolecular associations in dilute system", Polymer, V. 44, No. 26, 2003 , pp. 7917-7924.

35. Palacios, M.; Flatt, R.J.; Puertas, F.; and Sanchez-Herencia, A.; "Compatibility between Polycarboxylate and Viscosity-Modifying Admixtures in Cement Pastes", Proceedings of the $10^{\text {th }}$ International Conference on Superplasticizers and Other Chemical Admixtures in Concrete, Prague, 2012, pp. 29-42.

36. Aubry, T.; and Moan, M.; "Rheological behavior of a hydrophobically associating water soluble polymer". Journal of Rheology, V. 38, No. 6, 1994, pp.1681-1692. 